\title{
Students' perception of effect on basic clinical skills training in preclinical phase to national OSCE
}

Fadhilah, Marita $\bowtie$

Faculty of Medicine and Health Sciences, Syarif Hidayatullah Jakarta State Islamic University, Indonesia (maritafadhilah@uinjkt.ac.id)

\section{Auda, Riva}

Faculty of Medicine and Health Sciences, Syarif Hidayatullah Jakarta State Islamic University, Indonesia (riva_iwa@yahoo.com)

Ardini, Witri

Faculty of Medicine and Health Sciences, Syarif Hidayatullah Jakarta State Islamic University, Indonesia (w.ardini@yahoo.com)

\section{Risahmawati}

Faculty of Medicine and Health Sciences, Syarif Hidayatullah Jakarta State Islamic University, Indonesia (risahmawatidr@uinjkt.ac.id)

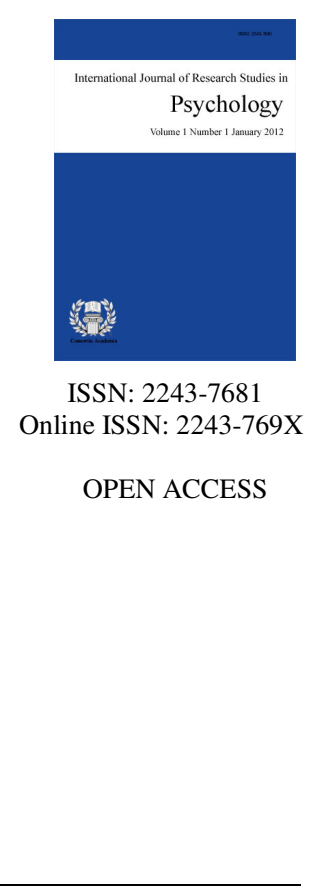

Received: 27 January 2015

\section{Abstract}

The aim of this study was to evaluate students' perception on effect of basic clinical skills (BCS) training in preclinical phase to national Objective Structured Clinical Examination (OSCE). Cross sectional study was conducted at Faculty of Medicine and Health Sciences (FMHS) during January and December 2013. After students finished national OSCE, they were asked to fill up questionnaire that comprised their perception on effect of BCS training in preclinical phase whether helpful to pass national OSCE. There were nine items questionnaire with Likert Scale of 1-5 (strongly disagree to strongly agree) and open question for comments. There were 50 students of total 53 students involved (response rate was $94.3 \%$ ). Generally students' perception on effect of BCS training to national OSCE was fair $(3.53 \pm$ 0.58). Students revealed that preclinical phase curriculum didn't effect to their succeed to pass national OSCE, whilst physical examination training gained the highest score $(3.38 \pm 0.87$ and $3.66 \pm 0.74$, respectively). Overall students' perception on effect of BCS training to national OSCE was fair. In the future, we have to revise our preclinical phase curriculum that integrate with BCS training curriculum and enhance students' clinical reasoning process to improve students' performance in national OSCE.

Keywords: students' perception; basic clinical skills training; national OSCE; integrated curriculum 


\section{Students' perception of effect on basic clinical skills training in preclinical phase to national OSCE}

\section{Introduction}

Faculty of Medicine and Health Sciences (FMHS), Syarif Hidayatullah Jakarta State Islamic University is one of the young medical schools in Indonesia. It was built on 2005 with 50 medical students for first year. In the same year, Indonesian Ministry of Science and Culture recommended to all of medical schools implementing Problem Based Learning (PBL) approach in preclinical years to cover Indonesian Medical Council required which called student centered, problem based, integrated, community based, elective, and systematic (SPICES). In that time, most of medical schools started to implement PBL approach in variety way including our institution. PBL is an appropriate learning method to create competent and professional doctor because it trains students to experience critical and constructive thinking (Schmidt, 1983). PBL approach focuses on student centered and using need to know-based learning activities. Students learn using clinical scenarios to explore learning objectives through small group discussion (SGD) and self-directed learning (SDL). Using PBL approach, students should not solve clinical problems but they use clinical problems as trigger to enhance their understanding of basic medical sciences and correlate with clinical problems (Wood, 2003).

It is well known that basic clinical skills (BCS) training is an effective way to introduce clinical skills experience in the preclinical setting since it improves students' performance in clinical setting (Blackley et al., 2009) and provides constructive feedback (Allery, 2009). Since 2005, we have been teaching BCS training such as communication, physical examination, data interpretation, and procedural skills among medical students in preclinical phase. It is such an early exposure to clinical phase for preclinical medical students and it could be bridging from preclinical phase to clinical phase. Thus, preclinical medical students get used to do an effective communication with simulated patients, choose and do an appropriate physical examination, get mastery of data interpretation, and get familiar on procedural skills. Those experiences shape students' self-confidence and reduce their anxiety before they face actual patients in the clinical phase at teaching hospital (Kalaça et al, 2004).

Meanwhile, evaluating students' BCS is also essential. Objective Structured Clinical Examination (OSCE) is one of reliable tool to assess those skills, such as physical examination and procedural skills, also communication skills, and professionalism which are difficult domain to assess (Amin, Seng, \& Eng, 2006). Miller (1990) proposed a framework (which was called Miller's pyramid) to assess students' competencies, from base of pyramid: 'knows' (knowledge), 'knows how' (competence), 'shows how' (performance), and the highest are 'does' (action). OSCE assess students' performance domain, students have to demonstrate and show how their clinical skills rather than know and know how.

Since its characteristics are precise, objective, and standardized, OSCE is used in broad range to assess students' clinical skills (Zayyan, 2011). On 2013 OSCE was implemented as national examination for all of Indonesian graduated medical students. National OSCE is conducted four times a year, on February, May, August, and November. Starting on August 2013 national OSCE was addressed as summative assessment. On 2014, national OSCE was declared officially as exit examination for all of Indonesian medical students. Those facts are big trigger to evaluate our BCS training, since we haven't evaluated it yet from the beginning. Therefore, we want to have better understanding about BCS training in preclinical setting that we have been doing for the past nine years using students' perception on effect of BCS in preclinical phase to national OSCE.

\subsection{Learning context}

As we know in PBL approach, SGD and SDL are the main learning activities in preclinical phase. For example in six weeks module, there are 25 hours for doing SGD and about 25-35 hours of SDL. In SGD, one 
group consists of 9 to 10 students who discuss under facilitation of one staff as facilitator. The other teaching methods are traditional lectures and laboratory works. Simultantly, BCS training are allocated about 20 hours. It is same with SGD; one group consists of 9 to 10 students with one staff as tutor. In each module we teach communication skills (i.e. history taking, breaking bad news, counseling, etc.), physical examination (i.e. thorax, abdomen, cranial nerves, etc.), additional examination (i.e. interpretation of electrocardiography results, laboratory findings, etc.), and procedural skills (i.e. vaccine injection, urine catheterization, intra venous injection, etc.). Each skills station is given two times, in the first meeting tutor demonstrate the content and students practice clinical skills under tutor supervision, and next meeting is formative assessment with meaningful feedback from tutor.

\begin{tabular}{|c|c|c|c|c|c|}
\hline & Monday & Tuesday & Wednesday & Thursday & Friday \\
\hline 7-8 am & \multirow{3}{*}{$\begin{array}{l}\text { Meet the } \\
\text { expert }\end{array}$} & \multirow{2}{*}{ Lecture } & \multirow{2}{*}{ Lecture } & \multirow{3}{*}{ SDL } & \multirow{3}{*}{ SDL } \\
\hline $8-9$ am & & & & & \\
\hline $9-10 \mathrm{am}$ & & \multirow{3}{*}{$\begin{array}{l}\text { Laboratory } \\
\text { work }\end{array}$} & \multirow{3}{*}{$\begin{array}{l}\text { Laboratory } \\
\text { work }\end{array}$} & & \\
\hline $10-11 \mathrm{am}$ & \multirow{2}{*}{ Lecture } & & & I octure & I sctur \\
\hline $11-12 \mathrm{am}$ & & & & Lecture & Lecture \\
\hline $12-1 \mathrm{pm}$ & \multicolumn{5}{|c|}{ LUNCH BREAK } \\
\hline $1-2 \mathrm{pm}$ & \multirow{2}{*}{ SGD } & BCS & BCS & \multirow{3}{*}{ SGD } & \multirow{3}{*}{ SDL } \\
\hline $2-3 \mathrm{pm}$ & & training & training & & \\
\hline $3-4 \mathrm{pm}$ & SDL & SDL & SDL & & \\
\hline
\end{tabular}

Figure 1. Timetable for SGD, SDL and BCS training for one week activities

OSCE is addressed for summative assessment of BCS training in the end of each year as known as regular OSCE and is incorporated with clinical reasoning module. It assesses all of clinical skills which has thought a whole year, but each station just assesses one students' clinical competency, each lasting seven minutes. In the end of preclinical phase to assure students' clinical skills mastery before entering the clinical phase program, we address comprehensive OSCE which assesses the whole preclinical clinical skills within three-years preclinical phase and each station assesses two to three students' clinical competencies with 12 minutes allocated. Both regular and comprehensive OSCE, in each station there is one rater. Recently, in regular and comprehensive OSCE we also involve simulated patient to encourage students' communication skills and professionalism behavior which are difficult domain to assess.

After students pass all of clinical rotations at teaching hospital, they have to take national OSCE since 2013. There were four periods of national OSCE have conducted at FMSH during 2013 (on February and May 2013 as formative assessment and on August and November as summative assessment). Twelve skills stations were administered with three to five students' clinical competencies at each station with 15 minutes allocated. Effective communication skills and professionalism behavior were assessed at all of stations. In each skills station there was one rater, except three stations there were two raters, one is from students' institution and another is from other institution.

\section{Methods}

Cross sectional study was conducted at FMHS during January and December 2013. In total, this study involved 53 students who have finished their all clinical rotation at teaching hospital. Unfortunately, we excluded three students because they didn't send back their questionnaires to us or the data was incomplete. On February 2013 we obtained 30 questionnaires, on May 2013 we obtained 11 questionnaires, on August 2013 we obtained eight questionnaires and on November we obtained only one questionnaire. All students have passed the same selection process, admission policy and entrance examination.

Just after students finished national OSCE, we explained the objectives of this study to students, provided 
the questionnaire form and asked them to fill up questionnaire that comprised their perception on effect of BCS training in preclinical phase whether helpful to pass national OSCE. As shown in table 1, there were nine items questionnaire with Likert Scale (1--strongly disagree, 2--disagree, 3--fair, 4-agree, and 5--strongly agree) and open question for comments. Completion time was flexible and we ensured privacy while completing the questionnaire. We guaranteed the students that the result would not affect their national OSCE's result. After they finished filled up the questionnaire, they sent back the completed questionnaire to us.

\section{Table 1}

Questionnaire about Students' Perception on Effect of BCS Training in Preclinical Phase to National OSCE

\begin{tabular}{ll}
\hline & \multicolumn{1}{c}{ Questionnaire Items } \\
\hline Q1 & BCS training curriculum helps you to pass national OSCE \\
Q2 & Preclinical phase curriculum helps you to pass national OSCE \\
Q3 & Communication skills training helps you to pass national OSCE \\
Q4 & Physical examination skills training helps you to pass national OSCE \\
Q5 & Procedural skills training helps you to pass national OSCE \\
Q6 & Regular OSCE helps you to pass national OSCE \\
Q7 & OSCE comprehensive helps you to pass national OSCE \\
Q8 & BCS facilities help you to pass national OSCE \\
Q9 & BCS tutors helps you to pass national OSCE \\
\hline
\end{tabular}

This study used quantitative and qualitative approaches. For quantitative approach we administered descriptive study. As further analysis, to find the interaction between factors of questionnaire items (Q1 until Q9 and mean total scores) and students' gender, also the interaction between factors of questionnaire items and type of assessment (formative and summative), those factors were incorporated into one way ANOVA. For qualitative approach we listed students' free comments and identifying frequent comments (more than or equals to three comments). Statistical analysis was performed with SPSS 21.0. P value of less than 0.05 was considered significant.

\section{Results}

There were 50 students of total 53 students involved (response rate was $94.3 \%$ ), consist of 36 male students and 14 female students. Forty-one students participated in February and May 2013 periods which was addressed as formative assessment, the other nine students participated in August and November 2013 periods which were addressed as summative assessment. Table 2 shows that generally students' perception on effect of BCS to national OSCE was fair $(3.53 \pm 0.58)$. Students revealed that preclinical phase curriculum (Q2) didn't effect to their succeed to pass national OSCE, whilst physical examination skills training (Q4) gained the highest score (3.38 \pm 0.87 and $3.66 \pm 0.74$, respectively).

\section{Table 2}

Questionnaire Items and Mean (SD) of Item Scores

\begin{tabular}{llc}
\hline & \multicolumn{1}{c}{ Questionnaire Items } & Mean Scores $(\mathrm{n}=50)$ \\
\hline Q1 & BCS training curriculum & $3.48(0.90)$ \\
Q2 & Preclinical phase curriculum & $3.38(0.87)$ \\
Q3 & Communication skills training & $3.52(0.78)$ \\
Q4 & Physical examination skills training & $3.66(0.74)$ \\
Q5 & Procedural skills training & $3.58(0.75)$ \\
Q6 & Regular OSCE & $3.58(0.72)$ \\
Q7 & OSCE comprehensive & $3.52(0.70)$ \\
Q8 & BCS facilities & $3.60(0.69)$ \\
Q9 & BCS tutors & $3.48(0.76)$ \\
\hline & Average of mean scores & $3.53(0.58)$ \\
\hline
\end{tabular}


Table 3

Interaction between Questionnaire Items and Students' Gender and Type of Assessment (Formative and Summative)

\begin{tabular}{llcc}
\hline & \multicolumn{1}{c}{ Questionnaire Items } & Gender $(\mathrm{p})$ & Type of Assessment $(\mathrm{p})$ \\
\hline Q1 & BCS training curriculum & 0.921 & $0.030^{*}$ \\
Q2 & Preclinical phase curriculum & $0.002^{*}$ & $0.021^{*}$ \\
Q3 & Communication skills training & 0.113 & 0.214 \\
Q4 & Physical examination skills training & 0.624 & 0.977 \\
Q5 & Procedural skills training & 0.332 & 0.119 \\
Q6 & Regular OSCE & 0.754 & $0.007 *$ \\
Q7 & OSCE comprehensive & 0.802 & $0.013^{*}$ \\
Q8 & BCS facilities & 0.645 & $0.019^{*}$ \\
Q9 & BCS tutors & 0.468 & 0.267 \\
\hline \multicolumn{2}{c}{ Aote. *Significantly difference using one way ANOVA } & 0.692 & $0.019^{*}$
\end{tabular}

Using one way ANOVA, we analyzed questionnaire items and students' gender and type of assessment. Table 3 shows that Q2-preclinical phase curriculum was significantly difference when related both factors students' gender and type assessment. Students who underwent the formative national OSCE were able to differs their ratings than students who underwent the summative national OSCE in some areas: BCS curriculum (Q1), preclinical phase curriculum (Q2), regular OSCE (Q6), OSCE comprehensive (Q7), BCS facilities (Q8) and average of mean scores.

Table 4

List of Students' comments and Its Percentage (totally $n=30$ )

\begin{tabular}{lll}
\hline No & & \multicolumn{1}{c}{ Students' Comments } \\
\hline 1 & Requiring try out before national OSCE & $8(27)$ \\
2 & Clinical phase skills training was helpful than BCS training & $6(20)$ \\
3 & BCS training and preclinical phase curriculum need improvement & $4(13)$ \\
4 & BCS tutors were not uniform & $3(10)$ \\
5 & BCS facilities were incomplete & $3(10)$ \\
6 & Some contents of BCS training were different from clinical phase skills training & $2(6.7)$ \\
7 & Clinical phase setting is different from national OSCE setting & $1(3.3)$ \\
8 & Physical examination skills training was helpful & $1(3.3)$ \\
9 & Requiring national OSCE socialization & $1(3.3)$ \\
10 & Suggesting OSCE for clinical phase assessment & $1(3.3)$ \\
\hline
\end{tabular}

Furthermore, we listed the three issues most frequent written related students' perception of the effect on BCS training to national OSCE based on their free comments (table 4): they asked FMSH conducted OSCE try out before the actual national OSCE (27\%), they felt that clinical phase skills training was more helpful than BCS training in preclinical phase $(20 \%)$ and BCS training and preclinical phase curriculum need improvement $(13 \%)$.

\section{Discussion}

The results showed that in general students' perception of the effect on BCS training in preclinical setting to their success in national OSCE was fair. It was predicted because we realized that especially in the beginning we run out BCS training with many limitations of human resources and facilities. Nowadays, some areas in BCS training still need more efforts from preclinical faculty to revise as shown in table 2 for these areas: preclinical phase curriculum, BCS training curriculum and BCS tutors (are classified as pre-BCS training domain). Those issues also represented in students' free comments.

Most probable reason why students revealed that preclinical phase and BCS training curriculum didn't affect their performance in national OSCE is preclinical phase and BCS training curriculum didn't integrate each other. 
Students couldn't correlate basic sciences knowledge when practicing BCS training. As mentioned before that BCS training is a bridge from basic sciences knowledge in the preclinical phase to clinical phase. It is not easy to pass the transition phase smoothly, it needs an integrated curriculum which correlates basic sciences and clinical reasoning process. First, students require to understanding clinical issues in basic sciences context, then interpreting clinical findings to do working diagnosis and appropriate therapy (van Gessel et al., 2003; Duthie Jr et al., 2004). Furthermore, Windish (2000) reported the teaching method that can make students are able to correlate basic sciences and clinical problems is using clinical reasoning process. Those evidences explained students' free comments that clinical skills training in clinical phase influenced their performance in national OSCE. Actually, students who are trained with BCS training and have experiences with PBL approach are more superior to students who in the traditional medical schools when they practice in the clinical setting. They are not only familiar with clinical skills, but raise good learning abilities during clinical phase (Remmen, 2001).

During 2005 to 2009, our preclinical staffs were still limited and in that time we haven't underwent to make BCS tutors uniform, tutors teach in same way at all the time. This issues caused students felt BCS tutors didn't help their performance in national OSCE.

Table 2 also showed that students rated physical examination skills training with highest score. In more details, we can note that physical examination skills, procedural skills and communication skills training (are classified as in-BCS training domain) have good students' rating score. Students expressed that those domain was helpful when they performed in national OSCE. This evidence related with previous study that BCS training could improve students' performance in OSCE (Jünger et al., 2005).

Of particular importance in this study was preclinical phase curriculum items achieved significantly difference for both factors students' gender and type of assessment. It means that male students' rating to preclinical curriculum items was different significantly from female students' rating. Similarly, students who took formative assessment have rated preclinical phase curriculum significantly from students who took summative assessment. Those facts made stronger the needs of preclinical phase curriculum with integration of basic and clinical sciences (van Gessel et al., 2003; Duthie Jr et al., 2004).

This study has two strengths. Firstly, since national OSCE implemented this is the first publication about evaluation BSC training in preclinical setting. Secondly, we used students' perception (both questionnaire and free comment), which seemed to successfully reflect students' actual feelings about their BCS experiences whether it helped their performance in national OSCE. Training evaluation using students perception is a crucial things, it has to align between students', preclinical faculty's and clinical faculty's expectations. Furthermore those synergies can develop appropriate curriculum especially BCS training curriculum which students-oriented approach (Wenrich et al., 2010) and establish tools which encourage clinical reasoning among students (Audétat et al., 2013). Despite its positive findings, this study has some limitations. Firstly, this study just enrolled small sample at one medical school rather than huge sample at multi center. Secondly, recall bias could influence the results because students have to remember their BCS training experiences in the preclinical phase within three to five years before.

For further study we have to survey preclinical and clinical faculty's expectations, also analyzing correlation between students' perception and their national OSCE scores, and establishing BCS training curriculum reform based on students' needs.

\section{Conclusion}

Overall students' perception on effect of BCS training to national OSCE was fair. In the future we have to revise our preclinical phase curriculum which integrate with BCS training curriculum and enhance clinical reasoning process to improve students' performance in national OSCE. 


\section{References}

Allery, L. (2009). Teach practical skills. Education Primary Care, 20(1), 58-60.

Amin, Z., Seng, C. Y., \& Eng, K. H. (2006). Practical guide to medical student assessment. Singapore, World Scientific Publishing Co. Pte. Ltd.

Audétat, M. C. et al. (2013). Clinical reasoning: Where do we stand on identifying and remediating difficulties?. Creative Education, 4(6A), 42-48. http://dx.doi.org/10.4236/ce.2013.46A008

Blackley, M., et al. (2009). Impact of a pre-clinical clinical skills curriculum on students' performance in third-year clerkships. Journal of General Internal Medicine, 24(8), 929-33. http://dx.doi.org/10.1007/s11606-009-1032-7

Duthie Jr, E. H. et al. (2004). A collaborative strategy for reciprocal integration of basic and clinical sciences. Medical Science Educator, 14(1), 34-38.

Jünger, J. et al. (2005). Effects of basic clinical skills training on objective structured clinical examination performance. Medical Education, 39, 1015-1020. http://dx.doi.org/10.1111/j.1365-2929.2005.02266.x

Kalaça, S. et al. (2004). What do we know about the anxieties of students starting clinical studies? Medical Science Educator, 14(1), 28-33.

Miller, G. E. (1990). The Assessment of Clinical Skills/Competence/Performance. Academic Medicine, 65(9), S63-S67. http://dx.doi.org/10.1097/00001888-199009000-00045

Remmen, R. et al. (2001). Effectiveness of basic clinical skills training programmes: a cross-sectional comparison of four medical schools. Medical Education, 35(2), 121-128. http://dx.doi.org/10.1046/j.1365-2923.2001.00835.x

Schmidt, H. G. (1983). The rationale behind problem based learning. Medical Education, 17, 11-16. http://dx.doi.org/10.1111/j.1365-2923.1983.tb01086.x

van Gessel, E. et al. (2003). Development of clinical reasoning from the basic sciences to the clerkships: a longitudinal assessment of medical students' needs and self-perception after a transitional learning unit. Medical Education, 37, 966-974. http://dx.doi.org/10.1046/j.1365-2923.2003.01672.x

Wenrich, M. et al. (2010). Ready or not? Expectations of faculty and medical students for clinical skills preparation for clerkships. Medical Education Online, 15, 5295. http://dx.doi.org/10.3402/meo.v15i0.5295

Windish, D. M. (2000). Teaching medical students clinical reasoning skills. Academic Medicine, 75(1), 90. http://dx.doi.org/10.1097/00001888-200001000-00022

Wood, D. F. (2003). ABC of learning and teaching in medicine: Problem based learning. British Medical Journal, 326(7384), 328-330. http://dx.doi.org/10.1136/bmj.326.7384.328

Zayyan, M. (2011). Objective structured clinical examination: The assessment of choice. Oman Medical Journal, 26(4), 219-222. http://dx.doi.org/10.5001/omj.2011.55 
